\title{
REACTIVE POWER CAPACITY ENHANCEMENT OF A PV-GRID SYSTEM TO INCREASE PV PENETRATION LEVEL
}

\author{
Ms.Preeta Singh $^{1}$ and Tarun Tailor ${ }^{2}$
}

\begin{abstract}
Prompted by the need for clean energy sources due to environmental constraint, increasing numbers of photovoltaic (PV) generators are being connected to electricity distribution systems around the world. Due to the high penetrations of such generators it is required to understand and quantify its technical impact on the operation and performance of electricity distribution systems. This paper proposes a novel scheme, where an auxiliary circuit (comprising an inverter and reactive power bank, RPB), in conjunction with a PV-grid system increases the system's reactive power compensation capacity. In spite of using only the conventional capacitor/inductor bank, the entire VAR range can be controlled. The proposed scheme enables the local Photovoltaic Distributed Generation System (PV-DGS) to provide the necessary reactive power support for the mitigation of large voltage variation on the feeder because of load variation and intermittent solar radiation. In order to properly predict these effects and to quantify them detailed modeling, analysis and control design is included in this work.

Keywords - Photovoltaic Distributed Generation System, reactive power compensation, PV penetration
\end{abstract}

\section{INTRODUCTION}

Distributed generation (DG) system has gained much popularity after a sustainable way of electric power system expansion and electrification of remote regions. Basically DG system includes decentralised smaller capacities power generators directly embedded within distribution network, or situated in proximity to the points of energy consumption [1]. Being a new option to replace centralised energy generation system, it often involves small-scale technologies for harnessing renewable (i.e. solar, wind, geothermal, biomass, biogas and hydroelectric power) energy sources [2]. Many problems can be experienced in the power system when DGs are added to the existing distribution network, due to the existing power system was designed to operate in a radial manner where the power flow is unidirectional, i.e., big centralized generating plants supplying power to loads downstream through long transmission. The present power grid as it is currently designed is still able to function appropriately when small amounts of DGs are added to the system. If the amount of the DGs added to the present grid go beyond a limit it is necessary to modify or change some of the existing power system equipment and protection. Without proper design and planning, the implementation of DGs in the distribution network will likely lead to power quality problems, degradation in system reliability, reduced efficiency, overvoltages and other safety issues. In a Distributed Generation embedded grid, the addition of DGs to the power distribution network can raise the voltage at PCC above the defined limit. The ANSI prescribes a limit of $\pm 10 \%$ of the nominal voltage as the acceptable voltage range. Fig. 1.2 depicts connection between a PV DG and the grid.

The consistent rise in load demand has led to new strategies for maximizing the production of electricity, including a alternative to local (distributed) generation. The reactive power control, in turn, supports increased PV penetration into the power system. As an extension of the proposed scheme, any existing conventional reactive power banks may be retrofitted with a given PV grid system to realize the proposed functionality. In general, PV systems use inverters to convert DC power from PV arrays to $60 \mathrm{~Hz}$ (or $50 \mathrm{~Hz}$ ) AC power grid standard [3, 4]. In addition to the basic inversion function, there are more functions and features that are common to grid-tied PV inverters such as:

\footnotetext{
${ }^{1}$ Department of Electrical Engineering SISTECH E, Bhopal, M.P, India

${ }^{2}$ Department of Electrical Engineering SISTECH E, Bhopal, M.P, India
} 
Maximum Power Point Tracking (MPPT), grid disconnection, phase-locked loop for tracking the terminal voltage and anti-islanding detection scheme. Some of these functions are required by interconnection codes and standards, such as UL 1741 [5] and IEEE Std. 1547 [6]. Moreover, some modern PV inverters have the capability to supply or absorb reactive power, independently of their production of real power, at essentially no extra cost. PV systems that are capable of providing reactive power support to the grid are now commercially available. High penetration level of PV on distribution system presents several opportunities and challenges for power distribution utilities. Furthermore, the dissertation aims to address research activities related to DG monitoring and control, understanding voltage regulation and stability, and establishing a basis for renewable DG penetration and aggregation. Standard mathematical models of various power system components, including PV source, inverter module have been studied. The studied models are implemented in Matlab/Simulink observe the transient response of the models. The influence of interconnected renewable source (i.e. PV-DGS) on power system voltage stability is investigated.

\section{SYSTEM DESCRIPTION}

The voltage stability behavior of the power system changes significantly when distributed resources are added to the grid as a result of the reconfiguration of the power flow. Therefore, prior to deploying DGs in the power system, it is necessary to properly model and analyze the impact of adding DGs at different locations in the grid. The power system generally experiences voltage instability when there is a real and/or reactive power imbalance between the generators and the loads.

The major obstacle for PV integration into existing medium / low voltage network is the induced voltage rise due to the reverse power flow along the distribution feeders. This phenomenon is bound to be intensified under higher penetration of PV sources. The radial feeder is simulated to evaluate the efficacy of the proposed reactive power enhancement scheme as show in Fig.1[7]. The loads are connected at different buses through step down transformer. The proposed reactive power control system is connected at bus 3 .

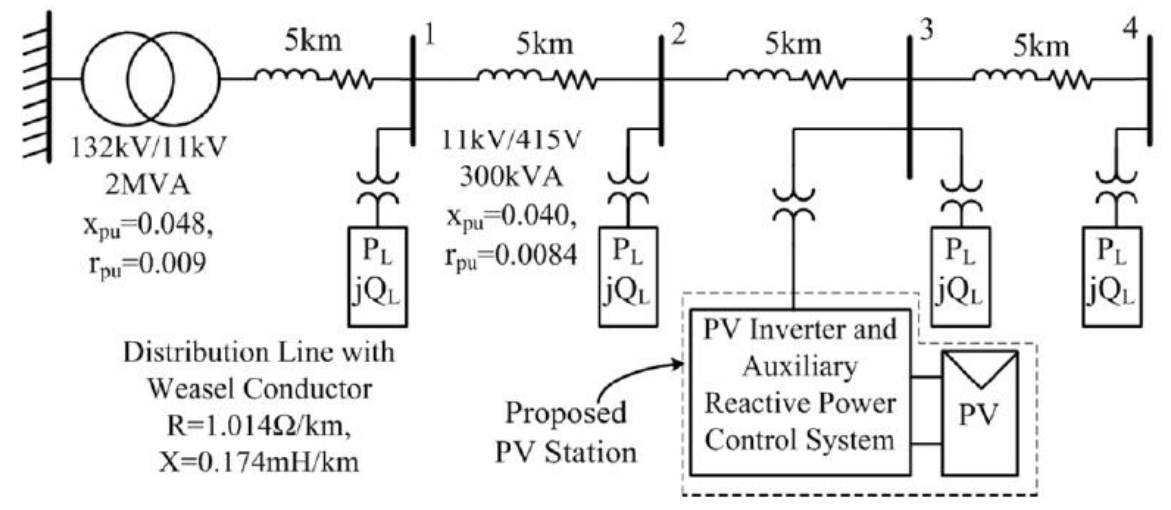

Fig. 1 Radial feeder single line diagram to study the proposed auxiliary converter and reactive power capability [7].

The PV system generally consists of PV array that converts the sunlight into electrical DC power and power conditioning unit. The power conditioning unit is responsible for converting the DC power into AC power, which is fed to the load center or power grid or local load. The battery is used as a storage device for storing DC power generated by PV array to improve the power availability. In the following sub-sections each component of PV system is described with mathematical modeling. The PV cells are the medium, which converts the solar energy into the electrical energy using photovoltaic effect. The PV effect is defined as the generation of electric voltage or current in a material by exposing light upon it. When sunlight incidents upon a material, the electrons present in the valance band get excited by the solar energy and jumps to the conduction band and become free. These extremely excited electrons diffuse and arrive to a junction where they are accelerated into a different material. This process causes the generation of an electromotive force and then light energy is converted into electrical energy by PV cell. The operation of a single PV cell can be explained via electrical equivalent circuit as shown in Fig. 3.

When an external supply is connected to the PV cell in dark (without sunlight), it will function as a normal diode and produce a diode current. Without sunlight the PV cell will not generate any electrical voltage or current. This PV cell model can be represented by a photocurrent source, a series and shunt resistance

i.e. internal resistances of each PV cell as well as equivalent resistances in joint between the cells and a diode as depicts in Fig. 3. 


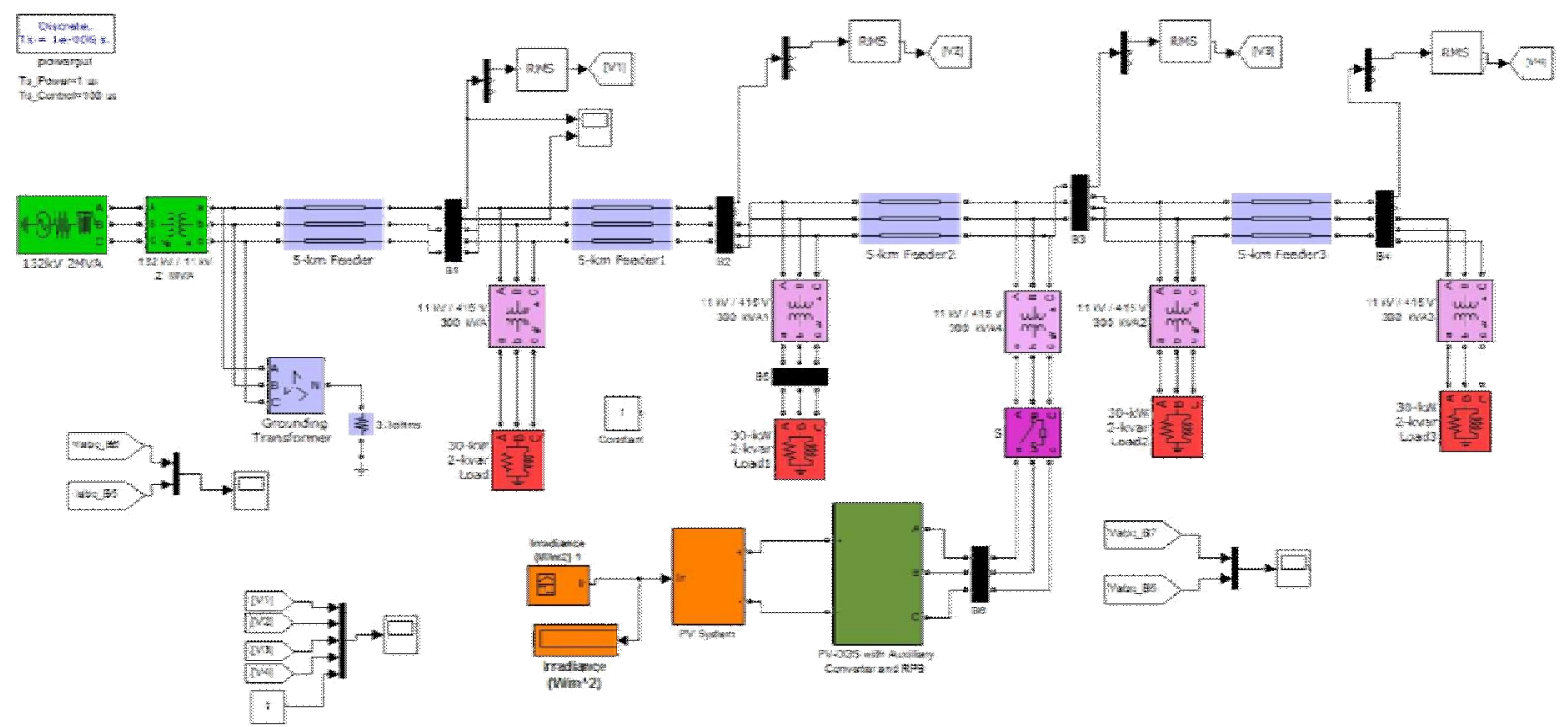

Fig. 2 Simulink Diagram of proposed system for study

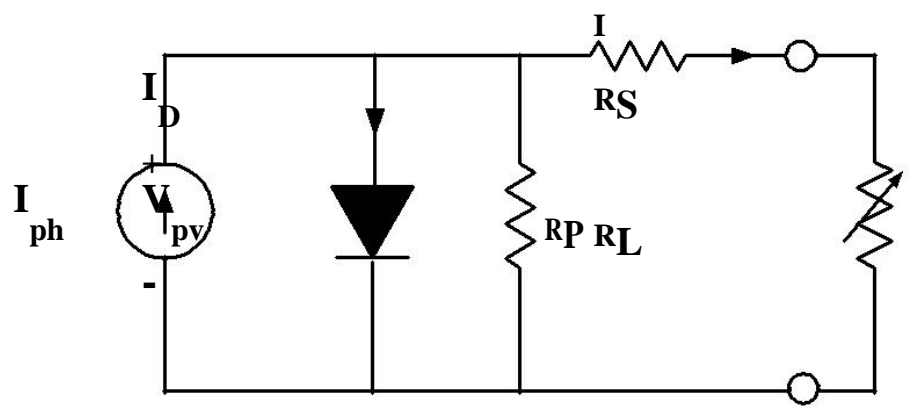

Fig. 3 Equivalent circuit of a single PV cell

The diode current can be expressed as:

Where, is the reverse saturation current of the diode and is the diode voltage. The voltage generated by the PV module is given by the eq. (2) as:

The current-voltage terminal characteristics of PV cell described mathematically is available in literature. The characteristic behavior of PV cell can also be derived by a single exponential equation (3),

The PV cell has some parameters such as short circuit current, open circuit voltage, cell voltage, current and power at maximum power point. The short circuit current is the current produced by PV cell under short circuited condition and voltage is zero. The open circuit voltage is the voltage drop across the diode under dark and current produced is zero. The open circuit voltage can also be expressed as:

The PV systems generally have PV arrays. The PV array or PV panel is the series and parallel combination of PV module and each PV module consists of group of series and parallel connected PV cell. 
The voltage generated by the PV panel can be expressed as:

The series and shunt resistances of the PV panel can be given as:

The PV power can be calculated using the following expression,

Using the eq. (2), eq. (3) and eq. (8), the V-I and P-V characteristic of PV cell can be plotted as shown in Fig. 4. The PV panel used in this research work is SunPower ${ }^{\mathrm{TM}} 305 \mathrm{PV}$ panel.

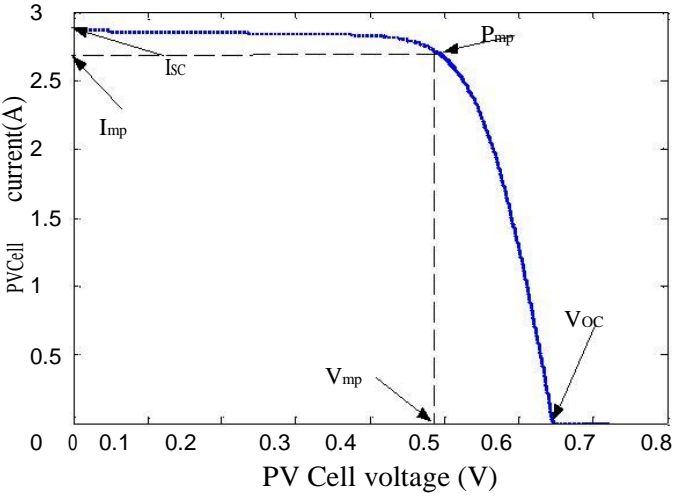

(a)

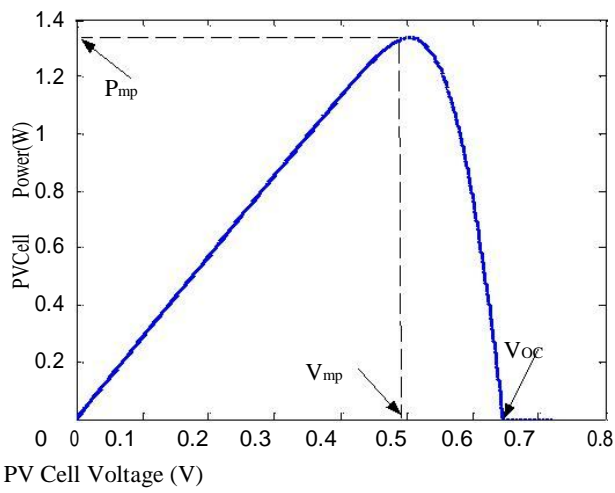

(b)

Figure 4 (a) V-I Characteristic of a single PV cell (b) P-V Characteristic of a single PV cell

According to maximum power transfer theorem, power delivered by the source to the load is maximum when the internal source impedance is approximately equal to the load impedance. The output power of the PV panel is variable according to the solar irradiance and temperature as shown in Fig. 5. Therefore, internal impedance of the PV panel is also variable according to variation in solar irradiance and temperature. The efficiency of the PV power generation is very low as compared to other renewable power generation. Therefore, for improving the efficiency of PV system, PV panel should be controlled to generate maximum power at variable solar irradiance and temperature. This feature can be provided by Maximum Power Point Tracking (MPPT) method. In this work, incremental conductance (INC) algorithm is used.

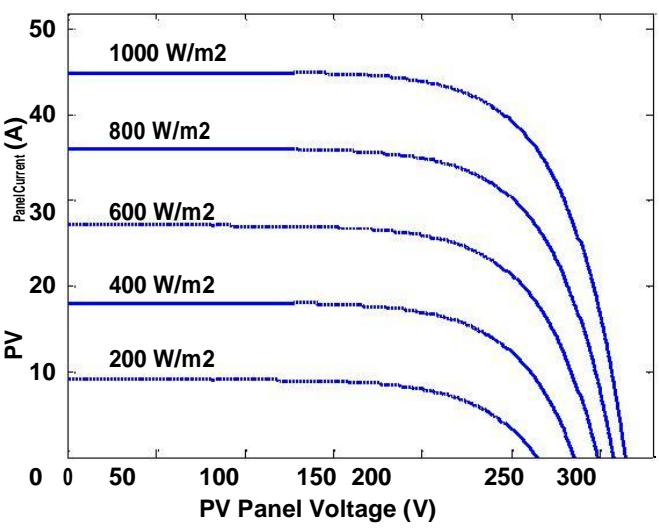

(a)

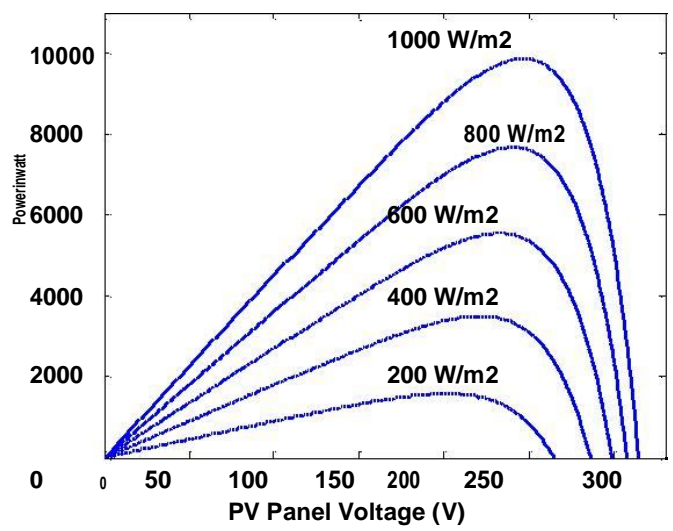

(b)

Fig. 5 Characteristic of PV panel at variable solar irradiance 


\section{Proposed Reactive Power Control Strategy}

This research focuses on addressing the challenges in Photovoltaic Distributed Generation System (PV-DGS) to provide the necessary reactive power support for the mitigation of large voltage variation on the feeder because of load variation and intermittent solar radiation. The PV-DG is connected at Bus-3 as shown in Fig. 1. The power circuit of PV-DG with auxiliary converter and reactive power bank (RPB) is shown in Fig. 6. The VSC 1 and $\mathrm{VSC}_{2}$ are the main PV-grid inverter and auxiliary converter respectively. The DC link voltage is controlled with the help of $\mathrm{VSC}_{1}$, therefore the PV generated power is represented by an equivalent current source $\mathrm{I}_{\mathrm{mp}}$. The bulk reactive power demand is supplied by fixed value capacitor bank $\mathrm{C}_{\mathrm{p}}$ and inductor bank $\mathrm{L}_{\mathrm{p}}$. The auxiliary converter is used with reactive power banks to regulate the RPB voltages equal to the grid voltage by drawing power from the DC link or PV source, while switch is open. The reactive power capacity of both converter and banks are considered equal. The control strategy incorporated for also handles the operation of switches $\mathrm{Sw}, \mathrm{Sw}_{1}, \mathrm{Sw}_{2}$, and $\mathrm{Sw}_{3}$. The low power rheostat $R_{p}$, is required for momentary changeover of the switches, across bank.

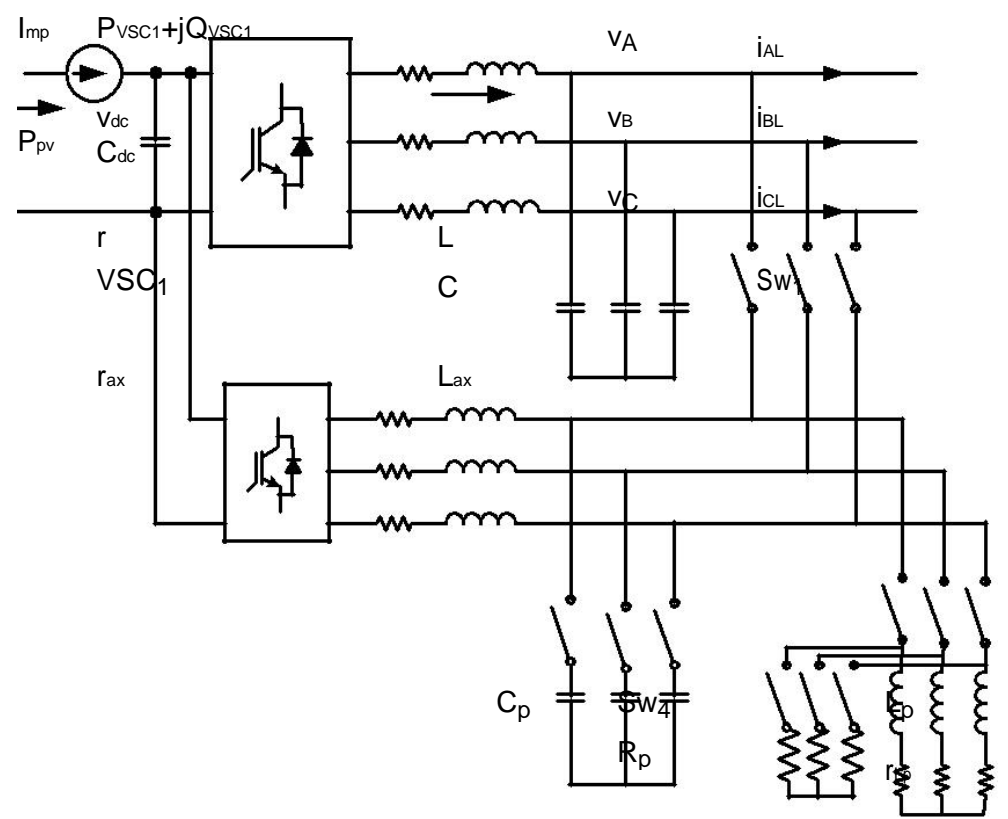

Fig. 6. Power circuit for PV-DG with auxiliary converter and RPB

The control strategy of $\mathrm{VSC}_{1}, \mathrm{VSC}_{2}$ and the various switches for the different operating conditions are represented in Table 1.

- $\quad$ In Case -I when Low Qstn Demand: Sw1 open, Sw2 and Sw3 close, Sw4 open, VSC2 regulates bank voltage. The reactive power demand of station is supplied by VSC1.

- $\quad$ In Case -II when High +Qstn Demand: VSC2 Off, Sw1 and Sw4 close, Sw3 open. The VSC1 controls surplus reactive power in addition to the capacitor.

- $\quad$ In Case -III when High -Qstn Demand: VSC2 Off, Sw1 close, Sw2 open, Sw3 close, Sw4 open. The VSC1 controls surplus or deficit reactive power in addition to the inductor reactive power.

Table 1. Proposed reactive power enhancement scheme.

\begin{tabular}{|l|l|l|}
\hline Case-I & Case -II & Case -III \\
Low Qstn Demand & High +Qstn Demand & High -Qstn Demand \\
\hline Sw1 open & VSC2 Off & VSC2 Off \\
Sw2, Sw3 close & Sw1, Sw4 close & Sw1 close \\
Sw4 open & Sw3 open & Sw2 open \\
VSC2 regulates bank voltage & Sw2 close & Sw3 close \\
& & Sw4 open \\
\hline
\end{tabular}

\section{Performance ANalysis Of The Proposed Scheme}

The proposed scheme as shown in Fig. 6 is modeled in MATLAB Simulink as shown in Fig 7. The power converters are accurately represented by detailed switch models. First of all performance of the auxiliary converter 
RPB configuration is investigated. In the normal operation (Case-I), DC link is regulated by VSC1. The VSC2, must be activated only after DC link is stabilized at the reference value set by $\mathrm{VSC}_{1}$. In order to synchronize bank voltages generated by $\mathrm{VSC}_{2}$ with the grid frequency and magnitude, components of grid voltage vector are applied as input reference signal to the outer AC voltage control loop of $\mathrm{VSC}_{2} . \mathrm{VSC}_{2}$ is activated when both $\mathrm{C}_{\mathrm{p}}$ and $\mathrm{L}_{\mathrm{p}}$ banks are connected $\left(\mathrm{S}_{2}, \mathrm{~S}_{3}\right.$ close) and switches $\mathrm{S}_{1}$ and $\mathrm{S}_{4}$ are open. Therefore, $\mathrm{VSC}_{2}$ supplies only the loss component and another current component due to minor difference between reactance values of $\mathrm{C}_{\mathrm{p}}$ and $\mathrm{L}_{\mathrm{p}}$. Fig. 8 depicts the low voltage and low current which indicate low VA capacity of $\mathrm{VSC}_{2}$.

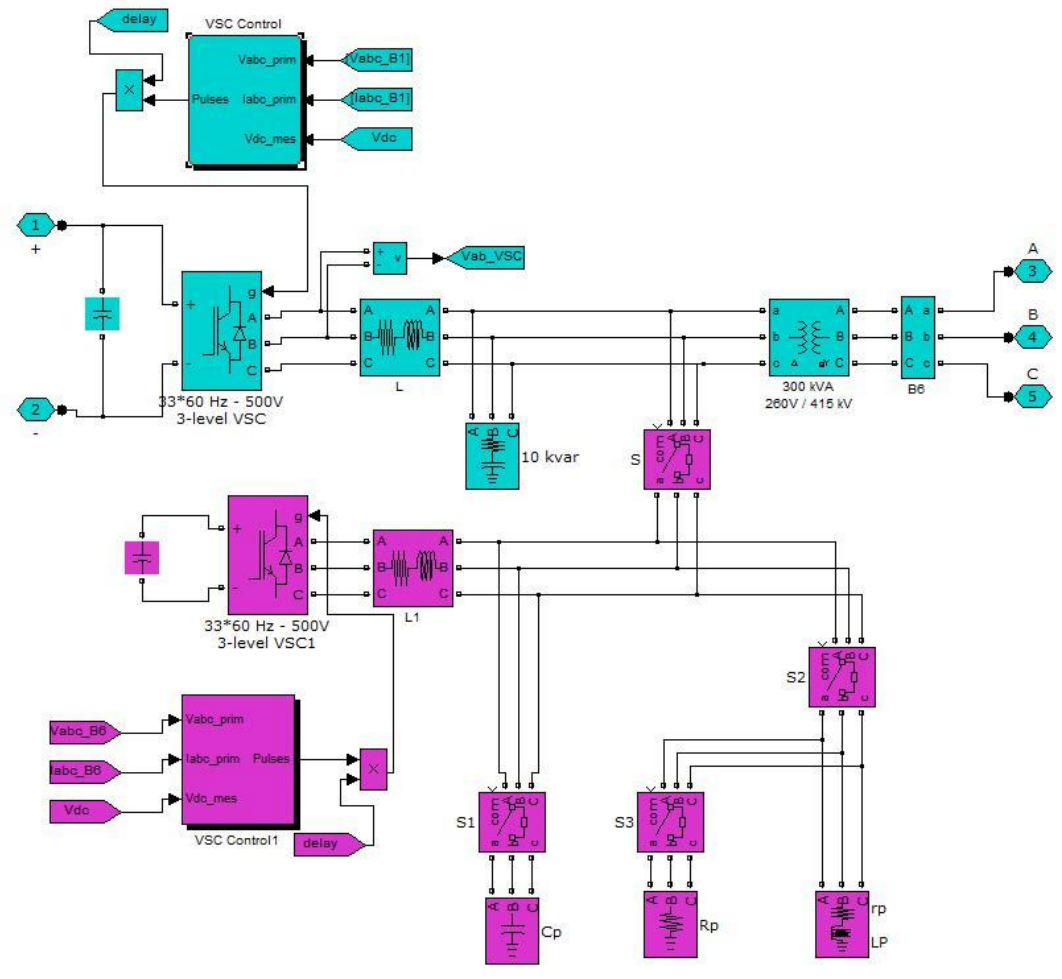

Fig. 7 Matlab simulink diagram of the proposed scheme

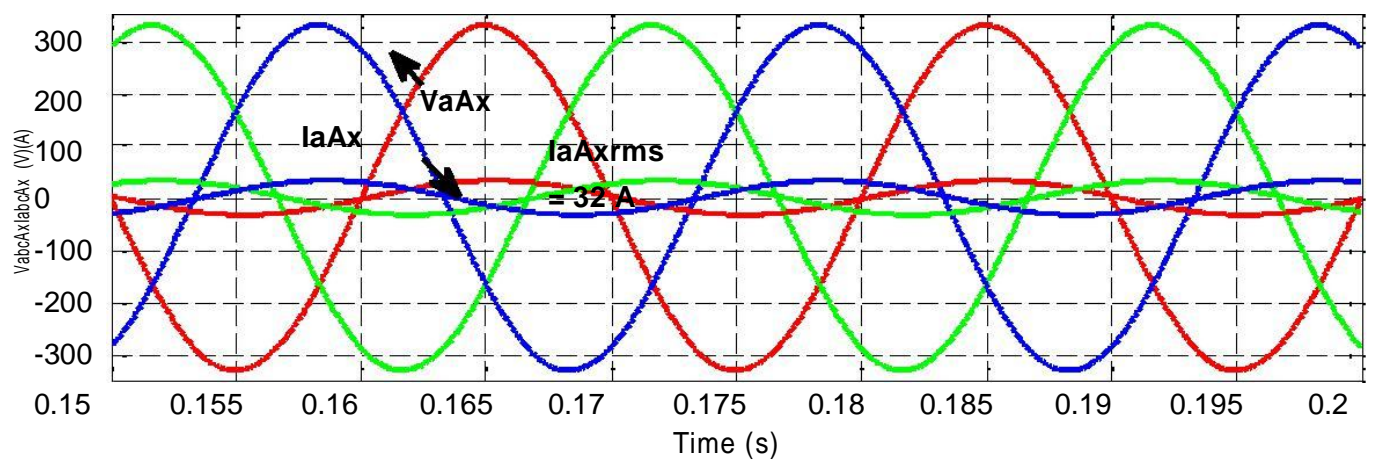

Fig. 8 3-Phase voltages and currents highlighting the low VA capacity $\mathrm{VSC}_{2}$.

Fig. 9(a) depicts a huge dip in the bus-3 voltage for the breaker operation at time instant, $t=0.06$ sec when conventional method of reactive power compensation is used in Fig. 1 instead of the proposed scheme. Due to the impact switching transients, not only bus-3, but other buses of the system are also affected severely as shown in Fig. 9(b). 


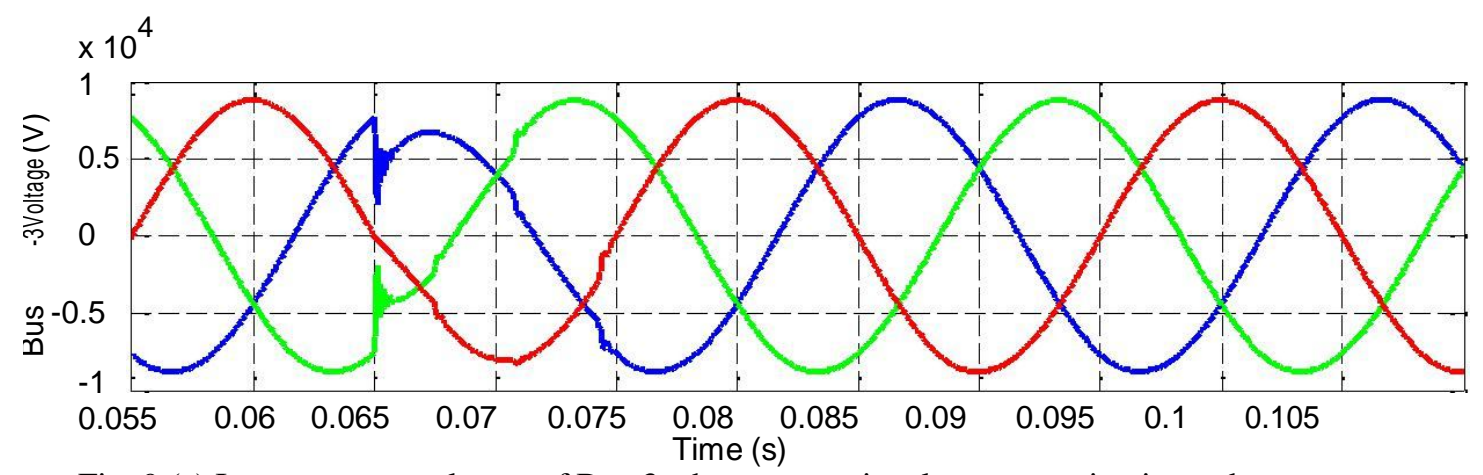

Fig. 9 (a) Instantaneous voltages of Bus-3 when conventional compensation is used

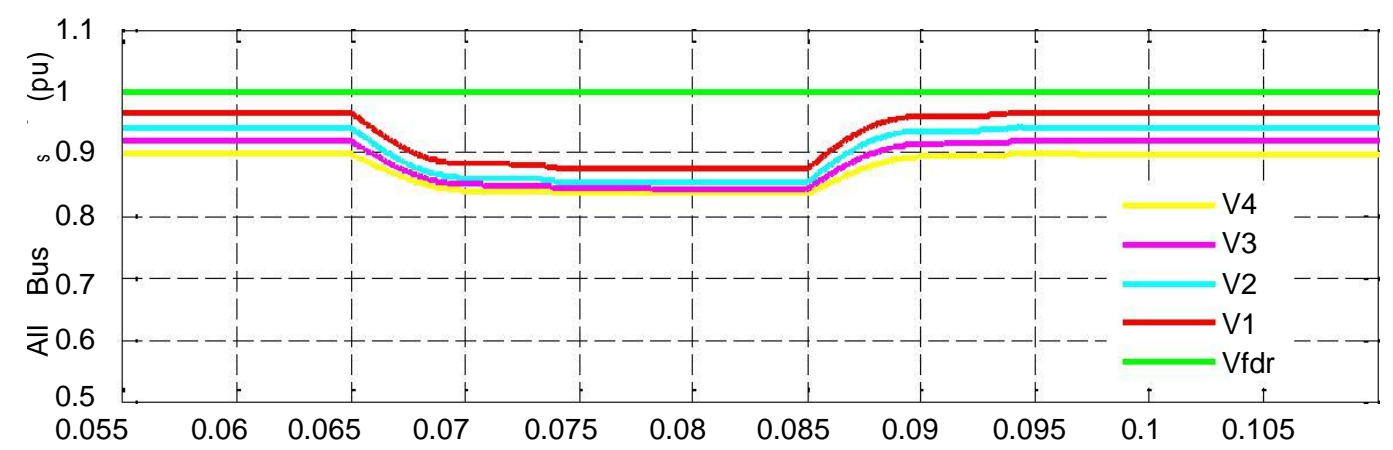

Time (s)

Fig. 9 (b) Per unit voltages all the buses of the system under study.

In the proposed scheme, the auxiliary converter coupled with the capacitor bank in the proposed system, ensures that the bank voltages are synchronized with the grid in frequency and magnitude during the switching of "Sw1" as shown in Fig. 10. From the Fig. 10 it is clear that no significant disturbances are observed compared to Fig. 9 during turn $\mathrm{ON}$ and $\mathrm{OFF}$ of " $\mathrm{Sw}_{1}$ " coupling and decoupling of RPB.

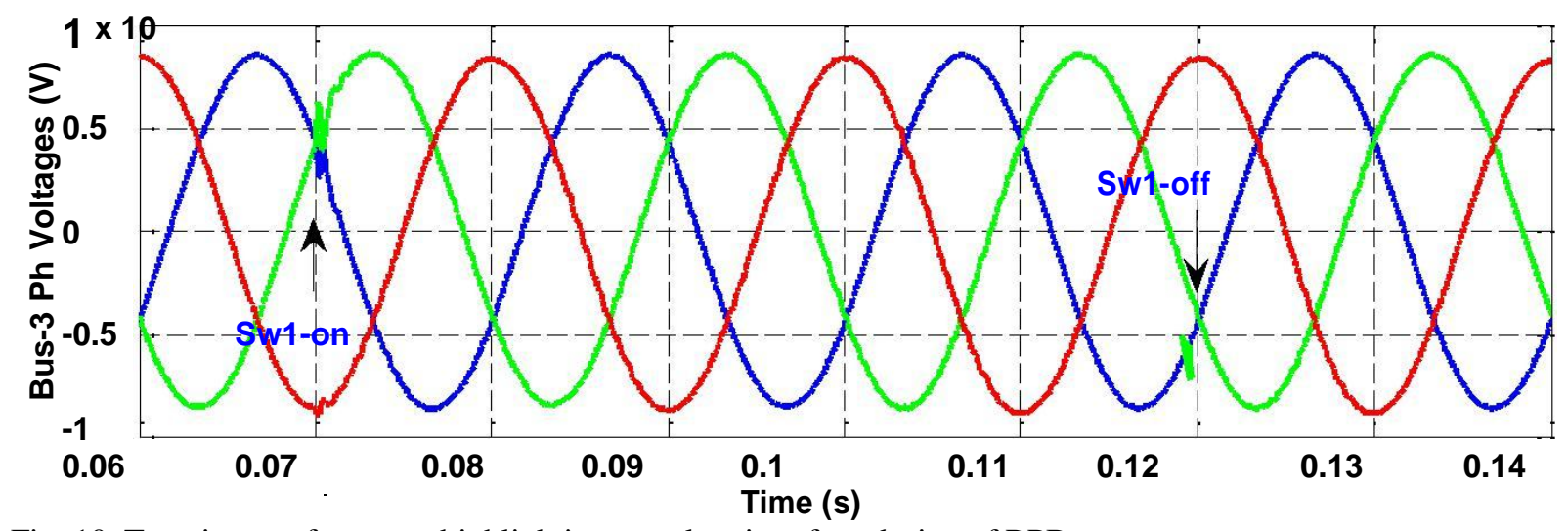

Fig. 10. Transient performance highlighting seamless interface during of RPB

\section{V.CONCLUSION}

Distributed power generation is being considered for reducing the stress on the power grid and reduction in transmission losses. The future power grid will have large number of inverter based distributed power generator like PV-DGs. However, with PV-DGs system reactive power compensation without hampering power quality is a challenging task. It is in this circumstance that the presented work assumes significance. It is clear from the result analysis the proposed scheme enhancing the reactive power capacity of the inverter based DGS. The conventional methods of compensation based on discrete L-C banks have detrimental effects on the waveforms of feeder voltage 
and its regulation. The proposed control scheme has presented these issues by eliminating switching transients and providing full range of reactive power control.

\section{REFERENCES}

[1] Alanne K, Saari A. Distributed energy generation and sustainable development. Renew Sustain Energy Rev 2006; 10:539-58.

[2] El-Khattam W, Salama MMA. Distributed generation technologies, definitions and benefits. Electr Power Syst Res 2004; 71:119-28.

[3] S. B. Kjaer, J. K. Pedersen, and F. Blaabjerg, "A review of single-phase grid connected inverters for photovoltaic modules," IEEE Trans. Ind. Appl., vol. 41, no. 5, pp. 1292-1306, 2005.

[4] J. Worden and M. Zuercher-Martinson, "How inverters work," SolarPro, Apr./May, 2009.

[5] Inverters, converters, controllers and interconnection system equipment for use with distributed energy resources, UL 1741.

[6] "IEEE standard for interconnecting distributed resources with electric power systems," IEEE Application Guide for IEEE Std 1547 (TM).

[7] R. G. Wandhare and V. Agarwal, "Reactive Power Capacity Enhancement of a PV-Grid System to Increase PV Penetration Level in Smart Grid Scenario," in IEEE Transactions on Smart Grid, vol. 5, no. 4, pp. 1845-1854, July 2014. 